Check for updates

Cite this: RSC Adv., 2019, 9, 17325

Received 12th March 2019

Accepted 20th May 2019

DOI: $10.1039 / c 9 r a 01891 c$

rsc.li/rsc-advances

\section{Sensitive electrochemical sensor based on poly( $L-$ glutamic acid)/graphene oxide composite material for simultaneous detection of heavy metal ions $\uparrow$}

\begin{abstract}
Wei Yi, ${ }^{a}$ Zihua $\mathrm{He}{ }^{a}{ }^{3}$ unjie $\mathrm{Fei}^{\mathrm{b}}$ and Xiaohua He (D) *a
Heavy metal pollution can be toxic to humans and wildlife, thus it is of great significance to develop rapid and sensitive methods to detect heavy metal ions. Here, a novel type of electrochemical sensor for the simultaneous detection of heavy metal ions has been prepared by using poly(L-glutamic acid) (PGA) and graphene oxide (GO) composite materials to modify the glassy carbon electrode (GCE). Due to the good binding properties of poly( $\left(\mathrm{-}\right.$-glutamic acid) (PGA) for the heavy metal ions (such as $\mathrm{Cu}^{2+}, \mathrm{Cd}^{2+}$, and $\mathrm{Hg}^{2+}$ ) as well as good electron conductivity of graphene oxide (GO), the heavy metal ions, $\mathrm{Cu}^{2+}, \mathrm{Cd}^{2+}$, and $\mathrm{Hg}^{2+}$ in aqueous solution can be accurately detected by using differential pulse anodic stripping voltammetry method (DPASV). Under the optimized experiment conditions, the modified GCE shows excellent electrochemical performance toward $\mathrm{Cu}^{2+}, \mathrm{Cd}^{2+}$, and $\mathrm{Hg}^{2+}$, and the linear range of PG/GCE for $\mathrm{Cu}^{2+}, \mathrm{Cd}^{2+}$, and $\mathrm{Hg}^{2+}$ is $0.25-5.5 \mu \mathrm{M}$, and the limits of detection (LODs, S/N $\geq 3$ ) $\mathrm{Cu}^{2+}, \mathrm{Cd}^{2+}$, and $\mathrm{Hg}^{2+}$ are estimated to be $0.024 \mu \mathrm{M}, 0.015 \mu \mathrm{M}$ and $0.032 \mu \mathrm{M}$, respectively. Moreover, the modified GCE is successfully applied to the determination of $\mathrm{Cu}^{2+}, \mathrm{Cd}^{2+}$, and $\mathrm{Hg}^{2+}$ in real samples. All obtained results show that the modified electrode not only has the advantages of simple preparation, high sensitivity, and good stability, but also can be applied in the field of heavy metal ion detection.
\end{abstract}

\section{Introduction}

With the development of industry and agriculture, a large amount of heavy metal ions $\left(\right.$ such as $\mathrm{Cu}^{2+}, \mathrm{Cd}^{2+}$, and $\mathrm{Hg}^{2+}$ ) are discharged into the ecological environment. The heavy metal ions can be accumulated into the human body through drinking water and food chain, severely endangering human health, and have become one of the public great attention focus in recent years. ${ }^{1}$ Hence, developing the effective, inexpensive and rapid heavy metal ion detections are highly urgent. Many methods have been developed and applied into detect the heavy metal ions including atomic absorption spectrometry, ${ }^{2}$ inductively coupled plasma mass spectrometry, ${ }^{3}$ and fluorescence spectrometry, ${ }^{4}$ et al. However, these classical methods applied in the field of heavy metal ion detection are limited due to their disadvantages of low sensitivity, high cost, and complicated operation. In contrast, the electrochemical methods, especially differential pulse anodic stripping voltammetry (DPASV), have been popularly used to detect the heavy metal ions because of their advantages of high sensitivity, simple operation, rapid

${ }^{a}$ School of Chemistry and Molecular Engineering, East China Normal University, 500 Dongchuan Road, Shanghai 200241, China.E-mail:xhhe@chem.ecnu.edu.cn ${ }^{b}$ Key Laboratory of Environmentally Friendly Chemistry and Applications of Ministry of Education, College of Chemistry, Xiangtan University, Xiangtan 411105, China

$\dagger$ Electronic supplementary information (ESI) available. See DOI: $10.1039 / \mathrm{c} 9 \mathrm{ra} 01891 \mathrm{c}$ analysis and low price. ${ }^{5}$ DPASV is a very sensitive electrochemical analysis method, which is widely applied in the analysis of ultrapure substances and environmental monitoring. ${ }^{6}$ Especially mentioned, composite materials used to modify the working electrodes for the heavy metal ion detections by using DPASV method have been an in-depth study in recent years. ${ }^{6,7}$ For example, Deshmukh and co-workers reported that the determination of the heavy metal ions $\mathrm{Cu}^{2+}$, $\mathrm{Pb}^{2+}$, and $\mathrm{Hg}^{2+}$ on the stainless steel electrode (SS) modified with ethylenediaminetetraacetic acid (EDTA) chelating ligand modified polyaniline ${ }^{8}$ and singe walled carbon nanotubes (SWCNTs) based nanocomposite (EDTA-PANI/SWNCTs), and the limit of detection the modified electrode toward $\mathrm{Cu}^{2+}, \mathrm{Pb}^{2+}$, and $\mathrm{Hg}^{2+}$ was determined as $0.08 \mu \mathrm{M}, 1.65 \mu \mathrm{M}$ and $0.68 \mu \mathrm{M}$, respectively. ${ }^{9}$ EDTA chelating ligand grafted onto PANI and SWCNTs improved the binding ability of heavy metal ions and the conductivity of the materials, respectively. At the same time, the research results also showed that the electron-conducting ability and the binding ability toward heavy metal ions of the composite materials are the key factors affecting the sensitivity of the modified electrode.

As a representative of $2 \mathrm{D}$ carbon materials, graphene oxide (GO) has been widely used to detect heavy metal ions in electrochemical analysis region. ${ }^{7 b, 8,10}$ This is mainly due to its good hydrophobicity, moderate conductivity, high chemical stability and excellent electrochemical properties, which is beneficial to improve the detection effect. Lu et al. prepared a series of heavy 
metal ions electrochemical sensors using reduced graphene oxide (rGO) material. ${ }^{11}$ Recently, our research group also reported the preparation of the reversible switched $\mathrm{pH}$-responsive hydroquinone electrochemical sensor based on composite film of polystyrene- $b$-poly(acrylic acid)/GO. ${ }^{12}$ On the other hand, poly(amino acid)s and their derivatives or analogues have also been applied for the development of bio/chemical sensors. ${ }^{5 f, 13}$ This is because poly (amino acid)s contain a large number of functional groups (such as carboxyl, amino), which can efficiently bind the detected substances (such as metal ions), thus improving the efficiency of their detection. Lin and co-workers reported a novel biosensor harnessing a peptide layer which has specific affinity to lead ion proved to be highly effective for electrochemical analysis of lead ions. ${ }^{13 \boldsymbol{b}}$ Benvidi etc. reported a novel sensitive electrochemical aptasensor based on poly ( $\mathrm{L}^{-}$ glutamic acid)/MWCNTs modified glassy carbon electrode for determination of tetracycline, which the combination of poly $\left(\mathrm{L}^{-}\right.$ glutamic acid)/MWCNTs is benefit to improve the detection limit of tetracycline. ${ }^{13 c}$ However, according to our best knowledge, the detection of heavy metal ions with poly (amino acid)s/ GO modified the electrode has been not reported.

Herein, we prepared a novel type of electrochemical sensor for the simultaneous detection of heavy metal ions $\mathrm{Cu}^{2+}, \mathrm{Cd}^{2+}$, and $\mathrm{Hg}^{2+}$, which was constructed through using poly(L-glutamic acid) (PGA) and graphene oxide (GO) composite materials to modify the glassy carbon electrode (GCE). Interest of the constructed electrochemical sensor originated from the following criteria: the ability to bind heavy metal ions with poly(L-glutamic acid) (PGA) due to many carboxyl groups on the side chain of PGA, the conductivity and chemical stability of GO, and their easy preparation and low-cost. In order to better improve the interaction between PGA with GO, porphyrin was introduced into PGA as a terminal group (see ESI, Scheme $1 \dagger$ ), which porphyrin with a conjugate ring structure can interact statically with the conductive materials (graphene, carbon nanotubes) by $\pi-\pi$ stacking interaction. ${ }^{14}$ The modified GCE with PGA/GO composite materials can used to quantitatively detect heavy metal ions $\mathrm{Cu}^{2+}, \mathrm{Cd}^{2+}$, and $\mathrm{Hg}^{2+}$ with both high sensitivity and wide linear detection range. Moreover, the modified electrode can be also used for the content analysis of $\mathrm{Cu}^{2+}, \mathrm{Cd}^{2+}$, and $\mathrm{Hg}^{2+}$ in practical samples, which can be a promising electrode for practical applications in heavy-metal-ion detection.

\section{Experimental section}

\subsection{Reagents and materials}

Graphene oxides (GO) was prepared in accordance with the method reported in the literature. ${ }^{15}$ Poly ( $\gamma$-benzyl-glutamate) with a terminal porphyrin group was prepared by using 5-(4aminophenyl)-10,15,20-tris(phenyl)porphyrin as an initiator according to the literature, ${ }^{16}$ poly (L-glutamic acid) (PGA) was synthesized according to a published procedure, ${ }^{17}$ and their detailed synthesis process were provided in the ESI. $\dagger \mathrm{CuSO}_{4}$, $\mathrm{CdSO}_{4}$, trifluoroacetic acid (TFA) were purchased from Aladdin Co. and used without further purification. $\mathrm{HgCl}_{2}$ was purchased from Sinopharm Chemical Reagent CO. Ltd (China) and used without further purification. $N, N$-Dimethylformamide (DMF) and other reagents used were of analytical grade and purchased from Shanghai Chemical Reagent Company of China. Ultrapure water $(18.2 \Omega)$ was used in the process of experiment.

\subsection{Fabrication of the modified electrodes}

Glassy carbon electrodes (GCEs) $(\Phi=3 \mathrm{~mm})$ were carefully polished with $0.3 \mu \mathrm{m}$ alumina and $0.05 \mu \mathrm{m}$ alumina in turn, and then treated in ethanol and ultrapure water for 3 minutes in an ultrasonic bath. Finally, GCEs were dried in the air before use.

PGA/GO (PG) suspension solution was prepared by mixing $1.0 \mathrm{~mL}$ of PGA solution $\left(10.0 \mathrm{mg} \mathrm{mL}^{-1}\right)$ in DMF and $1.0 \mathrm{~mL}$ of GO solution ( $3.0 \mathrm{mg} \mathrm{mL}^{-1}$ ) in DMF, and sonicating the mixture for 5 minutes. The modified working electrode, PG/GCE, was prepared by dropping $6 \mu \mathrm{L}$ PG suspension solution on a clean GCE surface and dried in vacuum at room temperature. For comparison, other modified electrodes, GO/GCE and PGA/GCE, were also prepared by the similar method by dropping GO solution and PGA solution, respectively.

\subsection{Characterizations}

Electrochemical experiments were carried out on a CHI 630 Electrochemical Workstation (Shanghai Chenhua Co., Ltd.) with a three-electrode system, consisting of a reference electrode of $\mathrm{Ag} / \mathrm{AgCl}$ electrode, a platinum wire auxiliary electrode, and a corresponding modified GCE. The electrochemical impedance spectroscopy (EIS) measurements were performed in a glass cell filled with $5 \times 10^{-3} \mathrm{M} \mathrm{Fe}(\mathrm{CN})_{6}{ }^{3-} / \mathrm{Fe}(\mathrm{CN})_{6}{ }^{4-}(1: 1)$ $+0.1 \mathrm{M} \mathrm{KCl}$ solution. Phosphate buffer solutions (PBS) were used as the supporting electrolyte. The whole electrochemical measurements were carried on air atmosphere. Hitachi S-4800 field-emission scanning electron microscopy with an accelerating voltage of $10.0 \mathrm{kV}$ was used to observe the surface morphologies of different films and samples were coated with a gold layer. ${ }^{1} \mathrm{H}$ NMR (500 MHz) spectrum was recorded on the Bruker DPX500 spectrometer using TMS as the internal standard of $\mathrm{CDCl}_{3}$.

\section{Results and discussion}

\subsection{SEM characterization}

The surface morphology of GO, PGA and PG films was investigated by SEM and the SEM images are depicted in Fig. 1. As shown in Fig. 1A, GO shows a smooth surface morphology with many fold structures. PGA is a homogeneous composite film with some small pleated structures (Fig. 1B), indicating its good film-forming property. On the surface of PG films, approximate uniform surfaces without macroscopic phase separation can be observed (Fig. 1C), indicating that they are well composited. This may be due to the strong interactions between some polar groups (such as hydroxyl, carboxyl groups, etc.) in GO and PGA chains.

\subsection{EIS of different electrodes}

The electron transfer properties of the electrodes were analyzed by electrochemical impedance spectroscopy (EIS). The semicircle diameter in the Nyquist plots directly reflects the electron 

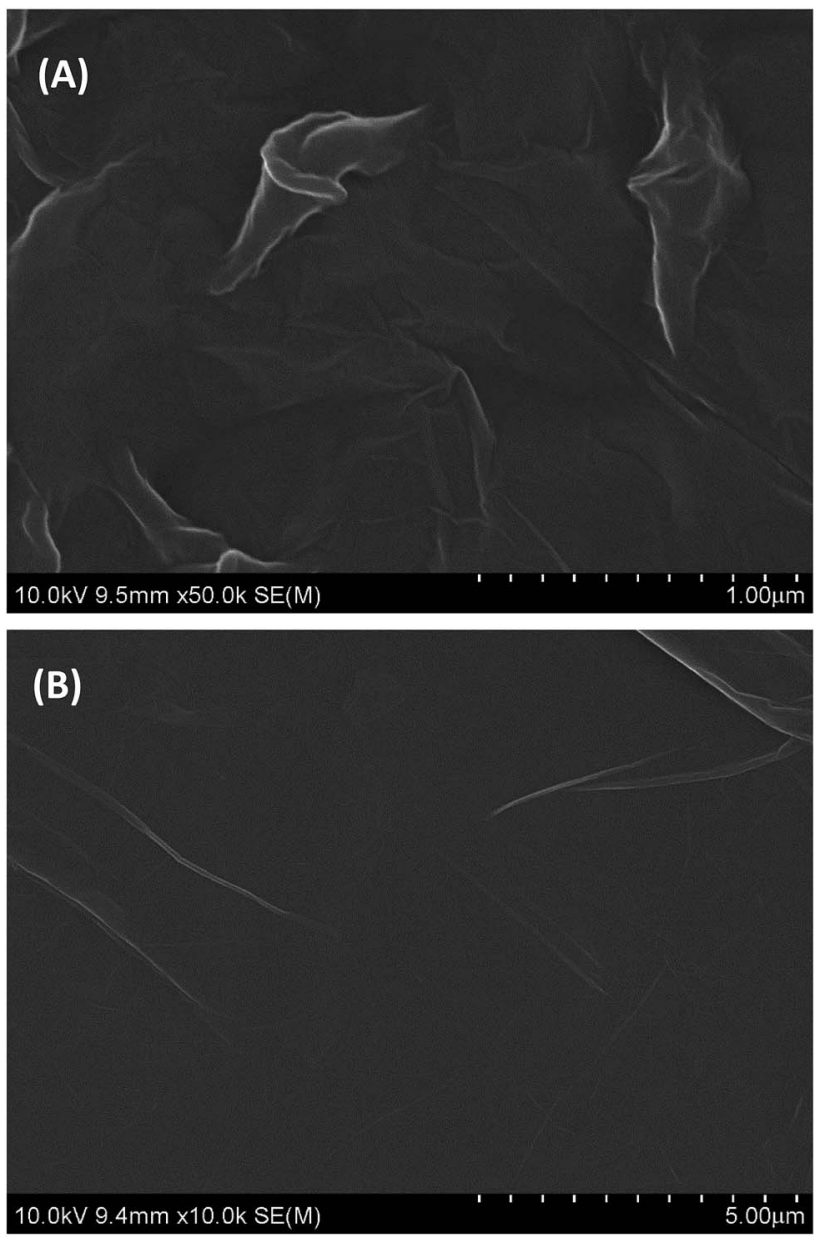

(C)

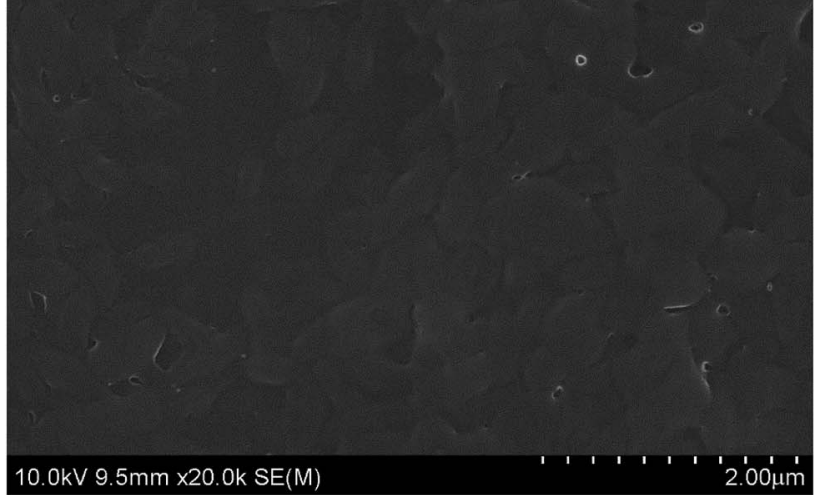

Fig. 1 SEM of (A) GO, (B) PGA film, and (C) PG composite film.

transfer resistance $\left(R_{\mathrm{et}}\right)$ at the electrode surface. ${ }^{18}$ Fig. 2 shows the results of EIS of different electrodes (Nyquist plots) toward soluble redox probes $\left[\mathrm{Fe}(\mathrm{CN})_{6}\right]^{3-/ 4-}$. Compared with the bare GCE (Fig. 2a), the redox process of the probes on the GO/GCE (Fig. 2c) hardly displayed electron transfer resistance, indicating that the prepared GO processes good electrical conductivity and the GO/GCE modified by GO has a faster electron transfer rate. At the same time, it also shows that GO can be

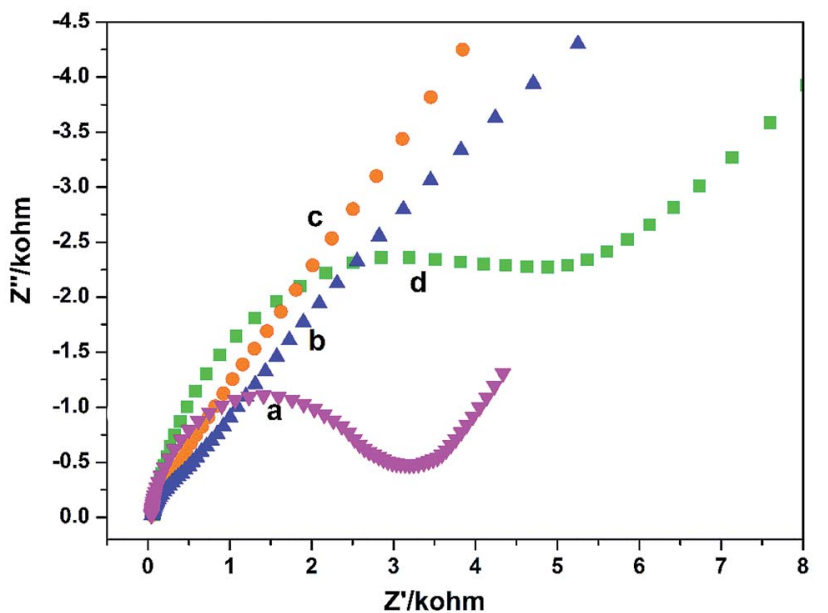

Fig. 2 EIS of (a) bare GCE, (b) PG/GCE, (c) GO/GCE, and (d) PGA/GCE in supporting electrolyte. Supporting electrolyte: $10 \mathrm{mmol} \mathrm{L}^{-1}$ $\mathrm{K}_{3}\left[\mathrm{Fe}(\mathrm{CN})_{6}\right] / \mathrm{K}_{4}\left[\mathrm{Fe}(\mathrm{CN})_{6}\right](1: 1)+0.1 \mathrm{~mol} \mathrm{~L}{ }^{-1} \mathrm{KCl}$ solution

successfully coated on the surface of the GCE. After modified the GCE by PGA, The semicircular diameter of the PGA/GCE (Fig. 2d) is much larger than that of the GCE (Fig. 2a), meaning that the $R_{\mathrm{et}}$ value of the PGA/GCE is much larger than that of the GCE, which is due to the poor conductivity of PGA. The semicircular diameter of the PG/GCE (Fig. 2b) is much smaller than that of the PGA/GCE, suggesting that the electron transfer resistance of the redox probe on the PG/GCE surface is much smaller than that of the PGA/GCE, which should be attributed to the good conductivity of GO. These results demonstrate that the PG/GCE electrode has been successfully prepared.

Electrochemical behaviors of metal ions at the bare GCE, PGA/GCE, GO/GCE, and PG/GCE were investigated by the cyclic voltammetry (CV). Fig. 3 depicts $\mathrm{CV}$ responses of $\mathrm{Cu}^{2+}, \mathrm{Cd}^{2+}$ and $\mathrm{Hg}^{2+}$ at the four electrodes in $0.1 \mathrm{~mol} \mathrm{~L}^{-1} \mathrm{PBS}$ buffer ( $\mathrm{pH}$ 6.5) at a scan rate of $100 \mathrm{mV} \mathrm{s}^{-1}$. Compared with PG/GCE and GO/GCE (Fig. 3 curve a and curve b), CV responses are severely suppressed at the bare GCE and PGA/GCE (Fig. 3 curve $c$ and curve d), which is mainly attributed the good electronic conductivity of GO, thus enhancing the electro-catalytic ability of the modified electrodes for the three metal ions. On the other hand, a pair of redox peaks on bare GCE (Fig. 3 curve c) are bigger than that on PGA/GCE (Fig. 3 curve d), indicating the poor conductivity of PGA. The results are also consistent with the EIS results. The anodic and cathodic peak currents at PG/GCE (Fig. 3 curve a) can be obviously observed and are much larger than those at GO/GCE (Fig. 3 curve b), demonstrating that the PG composite film enhances the electrochemical response and promotes the electronic transfer property of the PG/GCE electrode, which is mainly attributed the good binding ability between heavy metal ions with PGA due to many carboxyl groups on the side chain of PGA and the good interaction between the porphyrin terminal groups of PGA with GO. Moreover, the obviously increased current signals also proves that the PG film on the surface of the modified electrode, PG/GCE, is suitable for heavy metal ion 

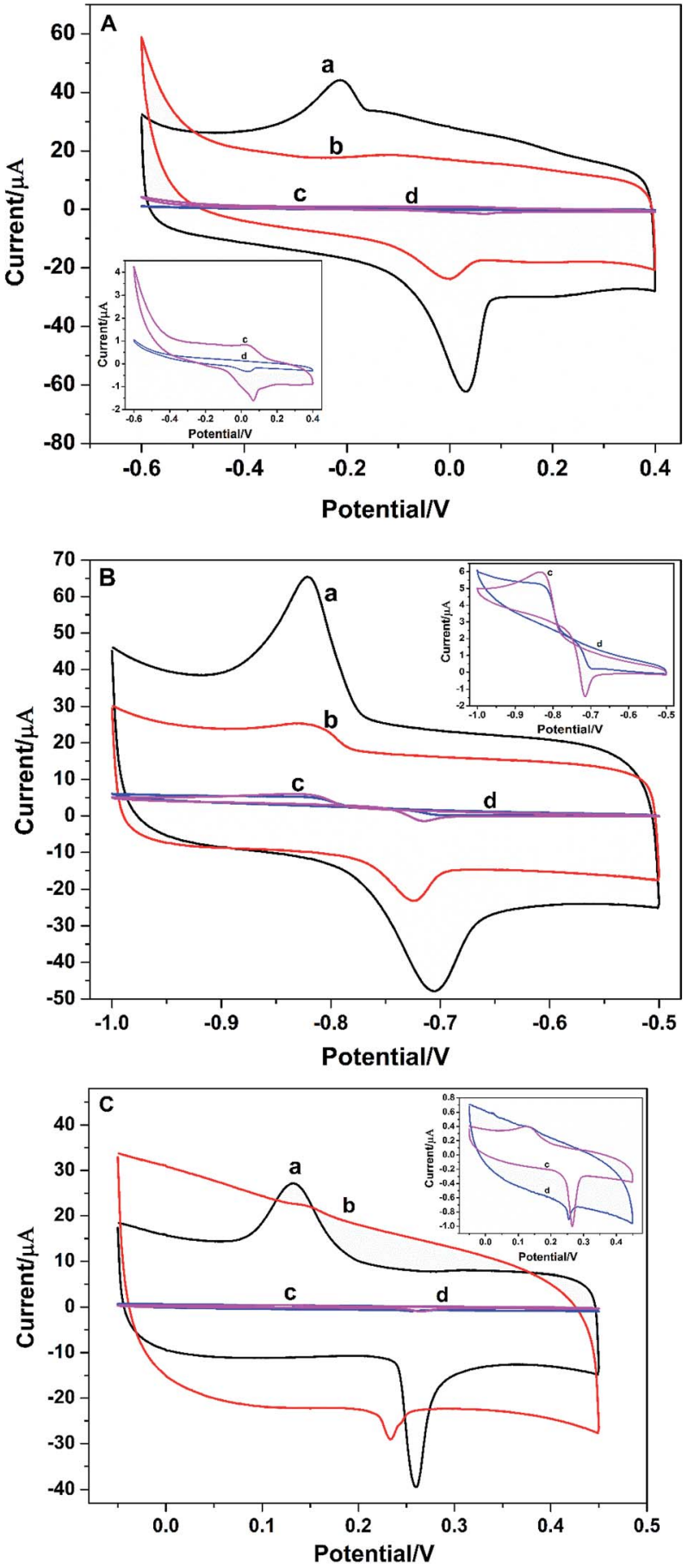

Fig. 3 (A) Cyclic voltammograms of $3.5 \mu \mathrm{MCu}^{2+}$ at $0.1 \mathrm{~V} \mathrm{~s}^{-1}$ for (a) PG/ GCE, (b) GO/GCE, (c) bare GCE, (d) PGA/GCE in 0.1 M PBS buffer (pH 6.5). (B) Cyclic voltammograms of $3.5 \mu \mathrm{M} \mathrm{Cd}^{2+}$ at $0.1 \mathrm{~V} \mathrm{~s}^{-1}$ for (a) PG/ GCE, (b) GO/GCE, (c) bare GCE, (d) PGA/GCE in 0.1 M PBS buffer (pH 6.5). (C) Cyclic voltammograms of $2.0 \mu \mathrm{M} \mathrm{Hg}^{2+}$ at $0.1 \mathrm{~V} \mathrm{~s}^{-1}$ for (a) PG/ GCE, (b) GO/GCE, (c) bare GCE, (d) PGA/GCE in $0.1 \mathrm{M}$ PBS buffer (pH 6.5).

detection, which is beneficial to increase the regional concentration and the detection limit of trace heavy metal ion. From the research results, PG/GCE has better electro-catalytic
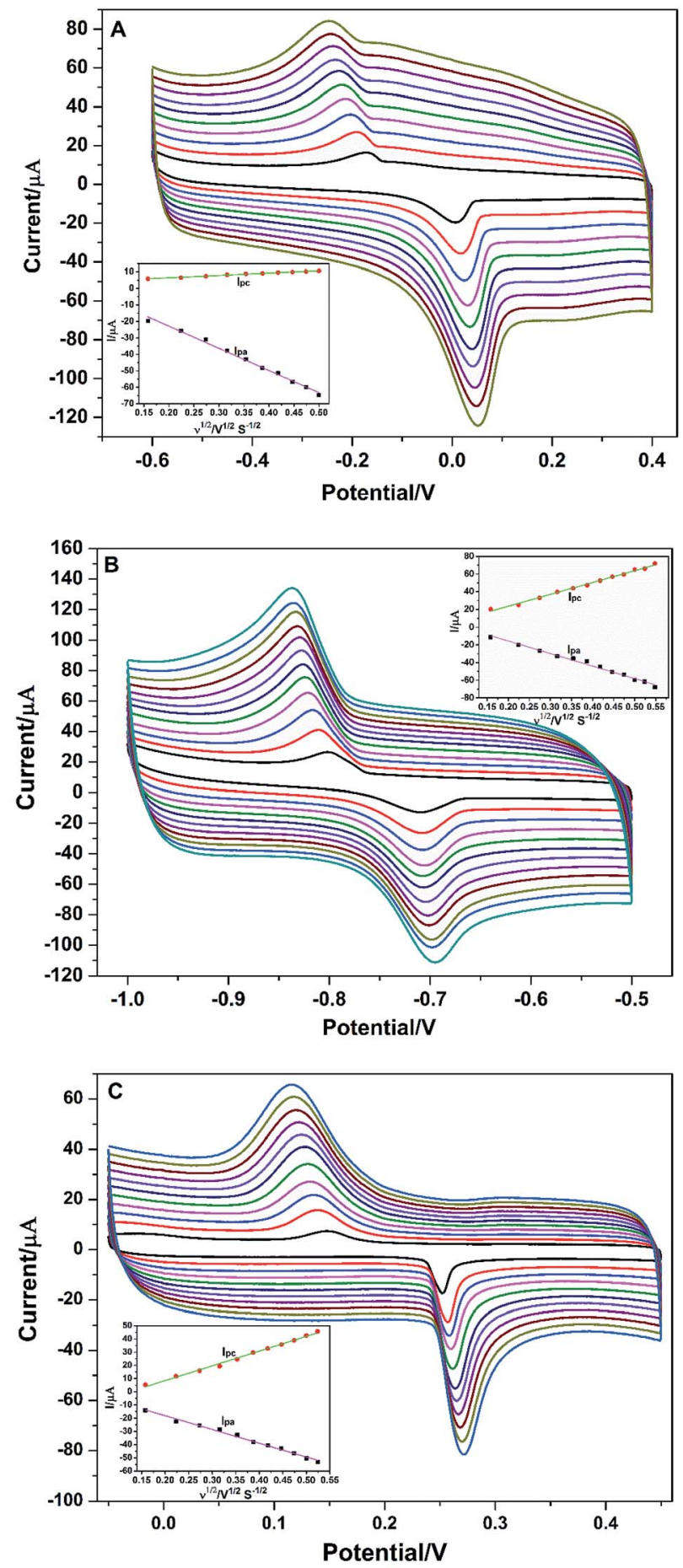

Fig. 4 (A) Cyclic voltammograms of $4.0 \mu \mathrm{MCu}^{2+}$ in $0.1 \mathrm{M} \mathrm{PBS}(\mathrm{pH} 6.5)$ at different scan rates on PG/GCE. (B) Cyclic voltammograms of 4.0 $\mu \mathrm{M} \mathrm{Cd}{ }^{2+}$ in $0.1 \mathrm{M} \mathrm{PBS}(\mathrm{pH} 6.5$ ) at different scan rates on PG/GCE. (C) Cyclic voltammograms of $2.0 \mu \mathrm{M} \mathrm{Hg}^{2+}$ in $0.1 \mathrm{M} \mathrm{PBS}(\mathrm{pH} \mathrm{6.5)} \mathrm{at}$ different scan rates on PG/GCE. Inset: plot of peak currents (I $/$ a and $\left.I_{\mathrm{pc}}\right)$ against the scan rate $(\nu)$.

performance toward $\mathrm{Cu}^{2+}, \mathrm{Cd}^{2+}$, and $\mathrm{Hg}^{2+}$. Therefore, PG/GCE exhibits the applicability towards $\mathrm{Cu}^{2+}, \mathrm{Cd}^{2+}$, and $\mathrm{Hg}^{2+}$ detection. 

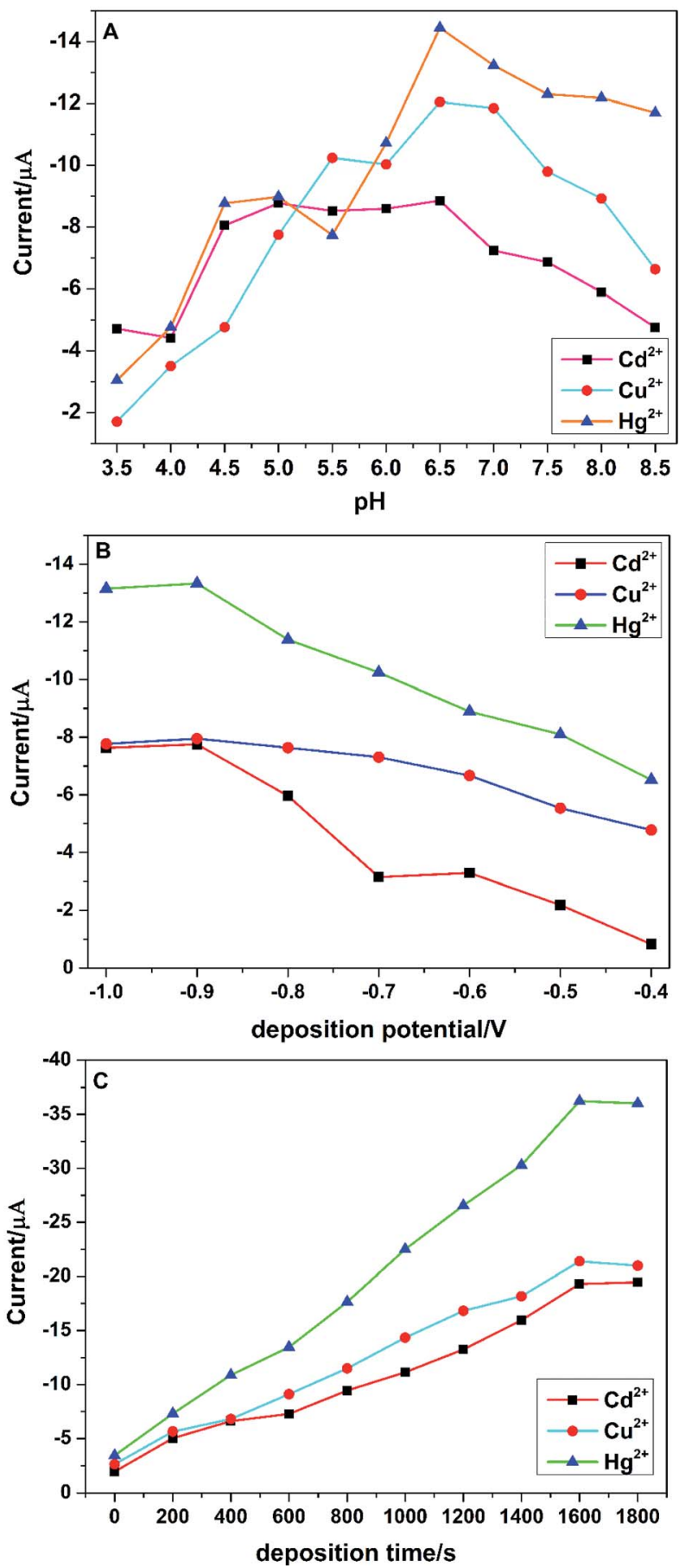

Fig. 5 (A) Effect of the electrolyte $\mathrm{pH}$ on the peak current of $2.0 \mu \mathrm{M}$ $\mathrm{Cu}^{2+}, \mathrm{Cd}^{2+}$ and $\mathrm{Hg}^{2+}$ in $0.1 \mathrm{M}$ PBS (deposition potential: $-0.9 \mathrm{~V}$, deposition time: $400 \mathrm{~s}$ ). (B) Effect of the deposition potential on the peak current of $2.0 \mu \mathrm{M} \mathrm{Cu}^{2+}, \mathrm{Cd}^{2+}$ and $\mathrm{Hg}^{2+}$ in $0.1 \mathrm{M}$ PBS $(\mathrm{pH}$ 6.5) (deposition time: $400 \mathrm{~s}$ ). (C) Effect of the deposition time on the peak current of $2.0 \mu \mathrm{M} \mathrm{Cu}^{2+}, \mathrm{Cd}^{2+}$ and $\mathrm{Hg}^{2+}$ in $0.1 \mathrm{M} \mathrm{PBS}$ (pH 6.5) (deposition potential: $-0.9 \mathrm{~V}$ ).

To better understand the redox reaction of $\mathrm{Cu}^{2+}, \mathrm{Cd}^{2+}$, and $\mathrm{Hg}^{2+}$ at PG/GCE, the effect of different scan rates on their redox peak currents was also performed by $\mathrm{CV}$ and the research results are shown in Fig. 4A series of well-define quasi-reversible redox waves are obviously observed (Fig. 4), and both the redox peak currents and the peak ( $E_{\mathrm{pa}}$ : an anodic peak potential)-topeak $\left(E_{\mathrm{pc}}:\right.$ a cathodic peak potential) separations $\left(\Delta E_{\mathrm{p}}: \Delta E_{\mathrm{p}}=\right.$ $\left.E_{\mathrm{pa}}-E_{\mathrm{pc}}\right)$ increase with increasing the scan rates. As seen from Fig. 4A, the anodic peak current $\left(I_{\text {pa }}\right)$ and cathodic peak current $\left(I_{\mathrm{pc}}\right)$ at PG/GCE in the potential range of $-0.6 \mathrm{~V}$ and $0.4 \mathrm{~V}$ for $\mathrm{Cu}^{2+}$ increase linearly proportional to the square root of the scan rates ranging from 0.025 to $0.25 \mathrm{~V} \mathrm{~s}^{-1}$ (inset of Fig. 4A), and linear regression equations between the electrode peak currents and the square root of the corresponding scan rates $\left(\nu^{1 / 2}\right)$ are expressed as $I_{\mathrm{pa}}=-4.03-134.58 \nu^{1 / 2}\left(R^{2}=0.993\right)$ and $I_{\mathrm{pc}}=$ $-3.60+14.20 \nu^{1 / 2}\left(R^{2}=0.995\right)$, where $R$ is the correlation coefficient. The results indicate that the electrochemical process of $\mathrm{Cu}^{2+}$ at PG/GCE is an adsorption control process. ${ }^{19}$ Fig. 4B shows the relationship between the redox currents of $\mathrm{Cd}^{2+}$ and the scan rates at $\mathrm{PG} / \mathrm{GCE}$ in the potential range of $-1.0 \mathrm{~V}$ and $-0.5 \mathrm{~V}$. With the increase of the scan rates, the electrode peak potentials of $\mathrm{Cd}^{2+}$ redox peaks hardly shift, but the electrode peak currents gradually increase. Electrode peak currents $\left(I_{\mathrm{pa}}\right.$ and $I_{\mathrm{pc}}$ ) have a good linear relationship with the square root of the scan rates $\left(\nu^{1 / 2}\right)$ at the scan rates ranging from 0.025 to $0.30 \mathrm{~V} \mathrm{~s}^{-1}$ (inset of Fig. 4B), and the linear equation between the electrode peak currents and the corresponding $\nu^{1 / 2}$ are expressed as $I_{\mathrm{pa}}=12.86-142.01 \nu^{1 / 2}\left(R^{2}=0.988\right)$ and $I_{\mathrm{pc}}=$ $-3.37+134.30 \nu^{1 / 2}\left(R^{2}=0.994\right)$. The results reveal that the electrochemical process of $\mathrm{Cd}^{2+}$ at PG/GCE is also controlled by an adsorption process. The electrochemical behavior of $\mathrm{Hg}^{2+}$ at PG/GCE was also performed by CV and shown in Fig. 4C. Very similar results can be obtained (Fig. 4C) and the electrode peak currents $\left(I_{\mathrm{pa}}\right.$ and $\left.I_{\mathrm{pc}}\right)$ at PG/GCE in the potential range of $-0.05 \mathrm{~V}$ and $0.45 \mathrm{~V}$ for $\mathrm{Hg}^{2+}$ increase linearly proportional to the square root of the scan rates $\left(\nu^{1 / 2}\right)$ ranging from 0.025 to $0.275 \mathrm{~V} \mathrm{~s}^{-1}$ (inset of Fig. 4C), which are expressed $I_{\mathrm{pa}}=2.75-104.30 \nu^{1 / 2}\left(R^{2}\right.$ $=0.995)$ and $I_{\mathrm{pc}}=-13.86+111.76 \nu^{1 / 2}\left(R^{2}=0.993\right)$, indicating that an adsorption-controlled process occur during the electrochemical process of $\mathrm{Hg}^{2+}$ at PG/GCE.

\subsection{Optimization of experimental parameters}

It was well known that the differential pulse anodic stripping voltammetry (DPASV) of the target heavy metal ions were sensitively dependent on the experimental analytical parameters, such as deposition potential, deposition time and $\mathrm{pH}$ of the supporting electrolyte. In order to obtain the best voltammetric responses of the PG/GCE towards the simultaneous detection of $\mathrm{Cu}^{2+}, \mathrm{Cd}^{2+}$, and $\mathrm{Hg}^{2+}$ by DPASV, three stripping analytical parameters such as deposition potential, deposition time and $\mathrm{pH}$ of the supporting electrolyte were fully investigated.

$\mathrm{pH}$ of the supporting electrolyte is another critical factor for the electrochemical detection of heavy metal ions. The effect of the supporting electrolyte $\mathrm{pH}$ on the tripping peak currents of $\mathrm{Cu}^{2+}, \mathrm{Cd}^{2+}$, and $\mathrm{Hg}^{2+}$ was examined from 3.5 to 8.5 and shown in Fig. 5A. The peak currents of the three target heavy metal ions increased with the increase of $\mathrm{pH}$ from 3.5 to 6.5, which may be due to the protonation of carboxylic groups at lower $\mathrm{pH}$ values and the decrease of their binding ability to metal ions. ${ }^{5 f}$ 


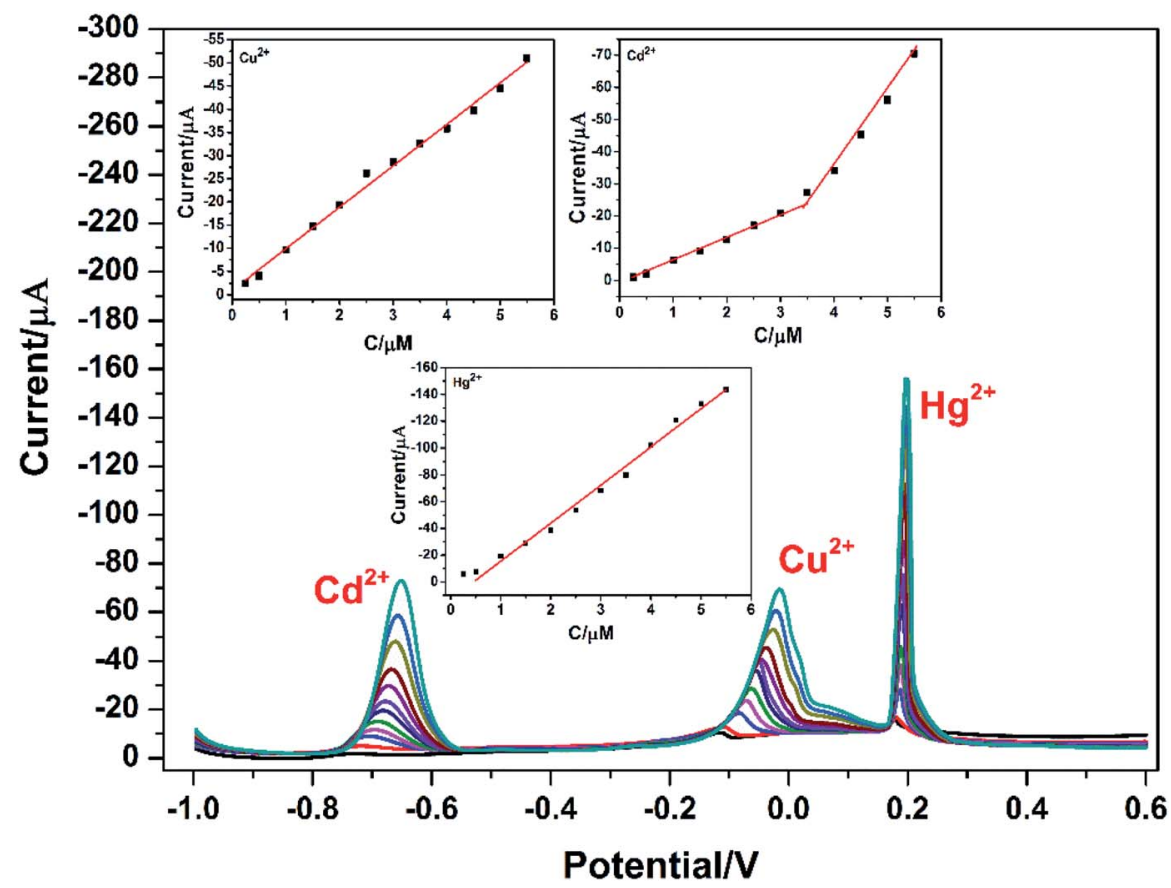

Fig. 6 DPASV for different concentrations of $\mathrm{Cu}^{2+}, \mathrm{Cd}^{2+}$, and $\mathrm{Hg}^{2+}$ at PG/GCE. The inset is a plot of the peak oxidation current value against its concentration.

However, the peak currents began to decrease when $\mathrm{pH}$ increased from 6.5 to 8.5 , which could be attributed to the formation of metal ions hydroxide complexes and the inhibition of their accumulation. ${ }^{20}$ Therefore, the supporting electrolyte at pH 6.5 was chosen throughout the experiments.

The effect of the deposition potential on the stripping responses of $\mathrm{Cu}^{2+}, \mathrm{Cd}^{2+}$, and $\mathrm{Hg}^{2+}$ in $0.1 \mathrm{M}$ PBS over the potential range of $-1.0 \mathrm{~V}$ to $-0.4 \mathrm{~V}$ after $200 \mathrm{~s}$ accumulation was investigated and shown in Fig. 5B. The biggest stripping currents are obtained at $-0.9 \mathrm{~V}$ for the three heavy metal ions and an obvious decrease of the stripping currents with a more positive deposition potential is observed, which may be attributed to the incomplete reduction of metal ions at a more positive potential. ${ }^{6}$ Therefore, $-0.9 \mathrm{~V}$ was chosen for the following experiments with high sensitivity and reproducibility. The effect of deposition time on the tripping peak currents was

Table 1 Comparison the analytical performances of PG/GCE electrode with other reported electrodes for the determination of $\mathrm{Cu}^{2+}, \mathrm{Cd}^{2+}$, and $\mathrm{Hg}^{2+a}$

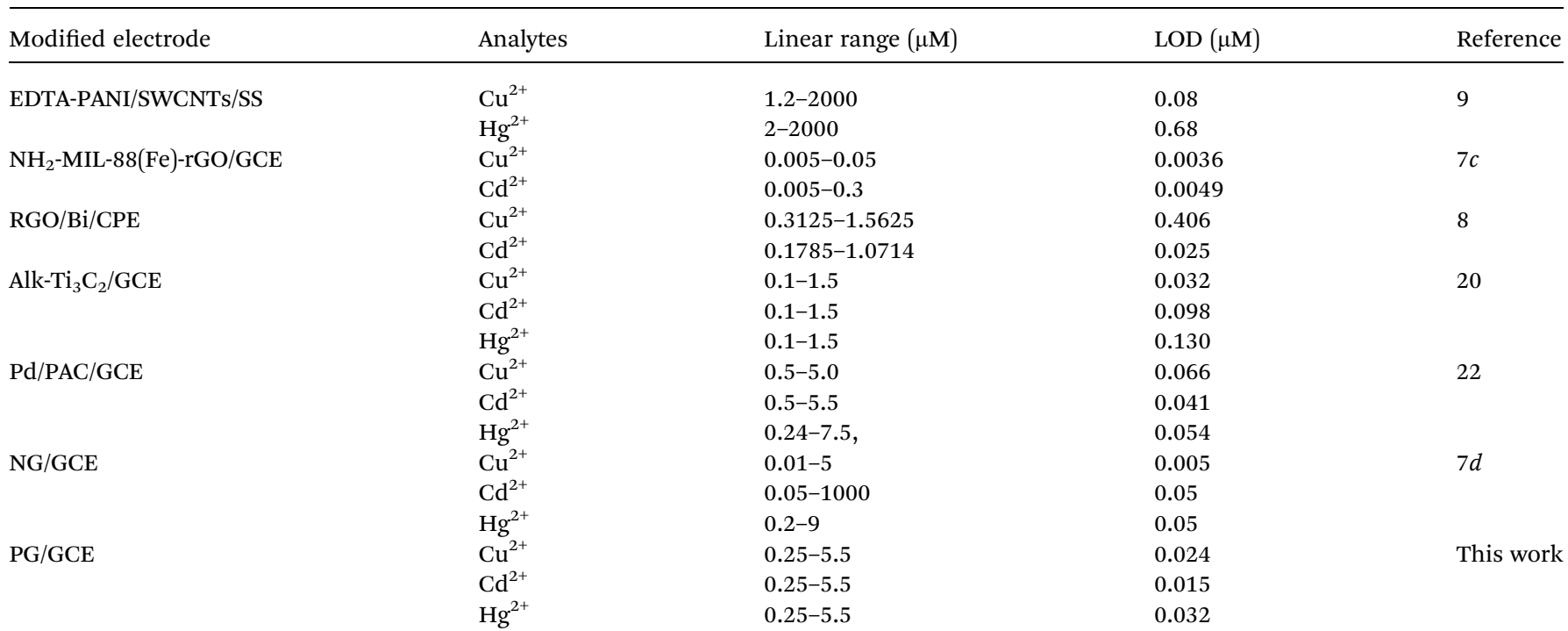

${ }^{a}$ EDTA: ethylenediaminetetraacetic acid. SS: stainless steel. Alk-Ti ${ }_{3} \mathrm{C}_{2}$ : alkaline-Ti ${ }_{3} \mathrm{C}_{2}$. PAC: porous activated carbons. NG: N-doped graphene. 


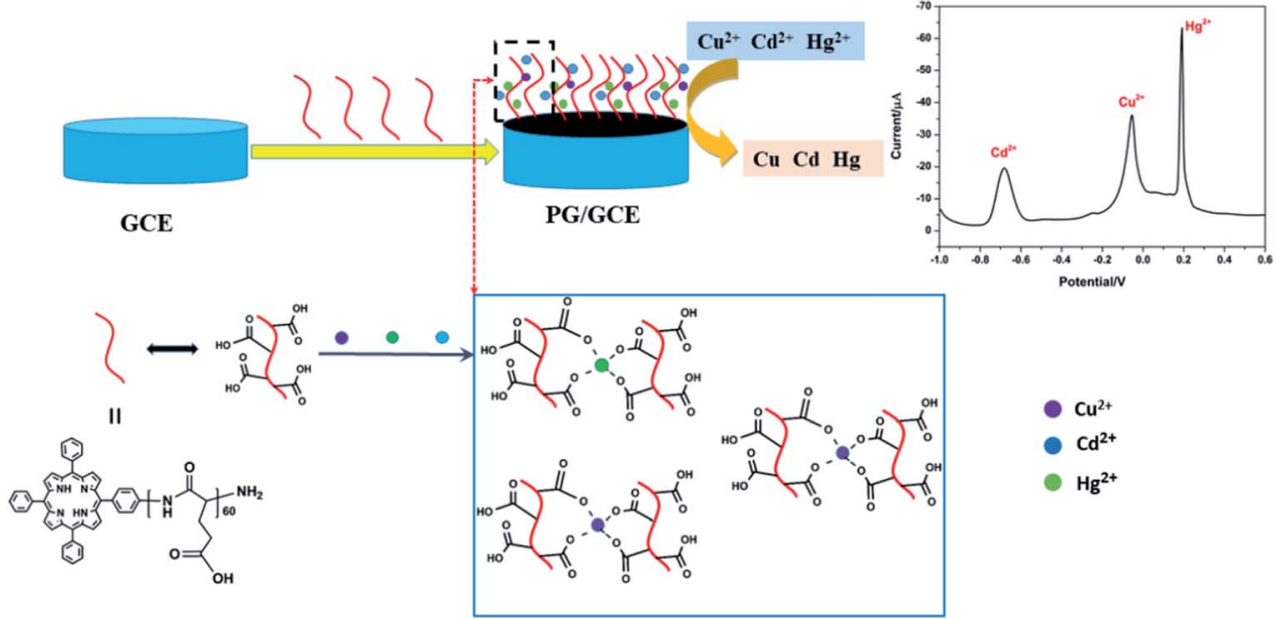

Scheme 1 Illustration the mechanism of $\mathrm{Cu}^{2+}, \mathrm{Cd}^{2+}$, and $\mathrm{Hg}^{2+}$ detection.
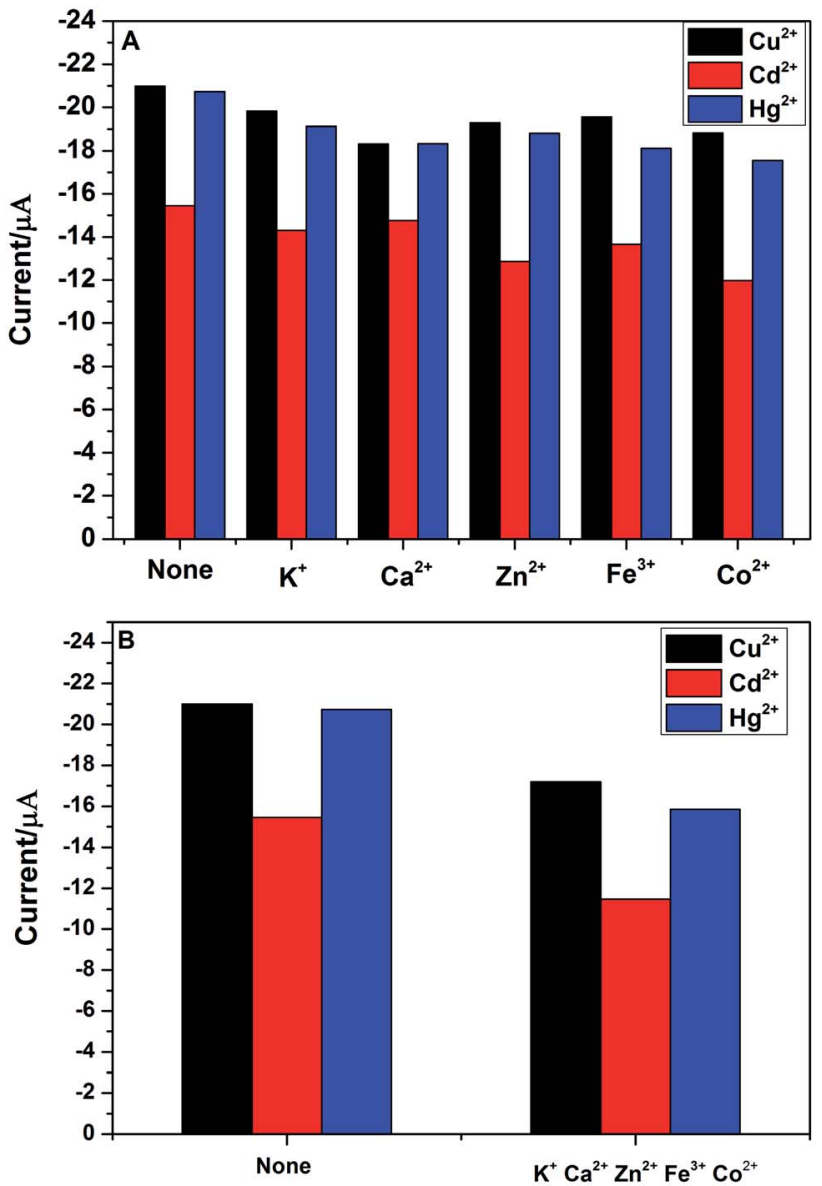

Fig. 7 (A) Effect of each interfering metal ions on detection of $2.0 \mu \mathrm{M}$ $\mathrm{Cu}^{2+}, \mathrm{Cd}^{2+}$ and $\mathrm{Hg}^{2+}$ in $0.1 \mathrm{M} \mathrm{PBS}(\mathrm{pH} 6.5)$. (B) Effect of five interfering metal ions on detection of $2.0 \mu \mathrm{M} \mathrm{Cu}^{2+}, \mathrm{Cd}^{2+}$ and $\mathrm{Hg}^{2+}$ in $0.1 \mathrm{M}$ PBS (pH 6.5).

also explored from $0 \mathrm{~s}$ to $1800 \mathrm{~s}$ and shown in Fig. 5C. The stripping peak currents increased almost proportionally with the increase of the deposition time from $0 \mathrm{~s}$ to $1600 \mathrm{~s}$, indicating that a longer deposition time would be benefit for the accumulation of metal ions on the surface the PG/GCE. However, when the deposition time was more than $1600 \mathrm{~s}$, the peak currents level off or slightly decreased, which may be due to the saturation of the surface active sites. ${ }^{20}$ Thus, the deposition time was selected as $1600 \mathrm{~s}$ for the simultaneous detection of $\mathrm{Cu}^{2+}, \mathrm{Cd}^{2+}$, and $\mathrm{Hg}^{2+}$.

\subsection{Analytical performance for simultaneous detection of $\mathrm{Cu}^{2+}, \mathrm{Cd}^{2+}$, and $\mathrm{Hg}^{2+}$}

Under the above optimized experimental parameters, DPASV measurements were carried out at PG/GCE for simultaneous detection of $\mathrm{Cu}^{2+}, \mathrm{Cd}^{2+}$ and $\mathrm{Hg}^{2+}$ by changing their concentrations from 0.25 to $5.50 \mu \mathrm{M}$, but keeping at a same concentration in their mixed solution for per detection. As shown in Fig. 6, three well-defined peaks without any overlapping for $\mathrm{Cd}^{2+}, \mathrm{Cu}^{2+}$ and $\mathrm{Hg}^{2+}$ are obviously observed at $-0.65 \mathrm{~V},-0.015 \mathrm{~V}$ and $0.2 \mathrm{~V}$, respectively. The peak currents increase linearly versus the $\mathrm{Cu}^{2+}$ and $\mathrm{Hg}^{2+}$ concentrations from 0.25 to $5.50 \mu \mathrm{M}$ (insets of Fig. 6) and the correction equations are $y=-0.939-8.95 x\left(R^{2}=\right.$ $0.993)$ and $y=13.023-28.454 x\left(R^{2}=0.995\right)(y:$ current $/ \mu \mathrm{A}, x$ : concentration $/ \mu \mathrm{M}$ ), respectively. The limit of detections (LOD) $(\mathrm{S} / \mathrm{N}=3)$ are calculated to be $0.024 \mu \mathrm{M}$ for $\mathrm{Cu}^{2+}$ and $0.032 \mu \mathrm{M}$ for $\mathrm{Hg}^{2+}$. However, as seen from the inset of Fig. 6, the analytic curves for $\mathrm{Cd}^{2+}$ covered two linear ranges varying from 0.25 to $3.5 \mu \mathrm{M}$ and 3.5 to $5.5 \mu \mathrm{M}$, and the corresponding correction equations are $y=1.329-7.291 x\left(R^{2}=0.995\right)$ and $y=50.76-$ $21.65 x\left(R^{2}=0.982\right)$, respectively. ${ }^{6}$ The limit of detection (LOD) for $\mathrm{Cd}^{2+}$ are calculated to be $0.015 \mu \mathrm{M}$ and $0.009 \mu \mathrm{M}$, respectively. It may be attributed to the two linear regions observed for $\mathrm{Cd}^{2+}$ that a dynamic equilibrium for $\mathrm{Cd}^{2+}$ adsorption and/or deposition can be gradually reached on the surface of PG/ GCE. $^{21}$ Table 1 summarized the comparison of the analytical performance for simultaneous detection of $\mathrm{Cu}^{2+}, \mathrm{Cd}^{2+}$ and $\mathrm{Hg}^{2+}$ at PG/GCE and that at other electrochemical sensors reported in recent years. In comparison with the reported values, PG/GCE shows both a wide linear range and a lower detection limit for 

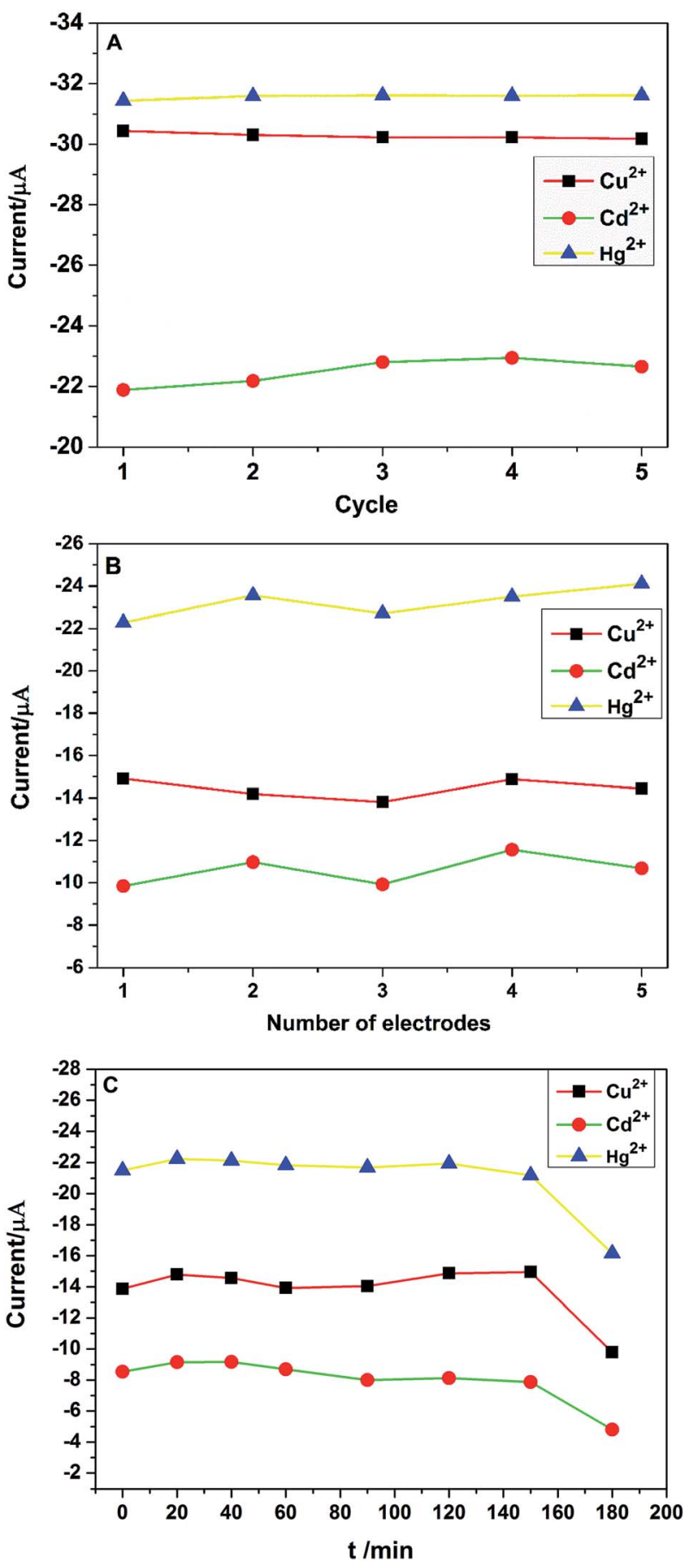

Fig. 8 (A) The oxidation peak current changes of PG/GCE for 5 repetitive measurements in $0.1 \mathrm{MPBS}(\mathrm{pH} 6.5)$ containing $2.0 \mu \mathrm{MCu}^{2+}$, $\mathrm{Cd}^{2+}$ and $\mathrm{Hg}^{2+}$. Scan rate: $0.1 \mathrm{~V} \mathrm{~s}^{-1}$; (B) the changes of oxidation peak current in $0.1 \mathrm{M}$ PBS (pH 6.5) containing $2.0 \mu \mathrm{M} \mathrm{Cu}^{2+}, \mathrm{Cd}^{2+}$ and $\mathrm{Hg}^{2+}$ with five different electrodes prepared in parallel. (C) The changes of oxidation peak current in $0.1 \mathrm{M}$ PBS $(\mathrm{pH} 6.5)$ containing $2.0 \mu \mathrm{M} \mathrm{Cu}^{2+}$, $\mathrm{Cd}^{2+}$ and $\mathrm{Hg}^{2+}$ with different soaking time of PG/GCE before initiating the measurement.

the detection of $\mathrm{Cu}^{2+}, \mathrm{Cd}^{2+}$ and $\mathrm{Hg}^{2+}$. The excellent analysis performance of PG/GCE may be attributed to the following factors: (i) PGA has a strong affinity for $\mathrm{Cu}^{2+}, \mathrm{Cd}^{2+}$, and $\mathrm{Hg}^{2+}$ due
Table 2 Detection results of $\mathrm{Cu}^{2+}, \mathrm{Cd}^{2+}$, and $\mathrm{Hg}^{2+}$ in lake water sample at $\mathrm{PG} / \mathrm{GCE}$

\begin{tabular}{llll}
\hline Analytes & Added $(\mu \mathrm{M})$ & Found $(\mu \mathrm{M})$ & Recovery $(\%)$ \\
\hline $\mathrm{Cu}^{2+}$ & 0 & - & - \\
& 0.3 & 0.299 & 99.7 \\
$\mathrm{Cd}^{2+}$ & 0.5 & 0.501 & 100.2 \\
& 0 & - & - \\
& 0.3 & 0.298 & 99.3 \\
$\mathrm{Hg}^{2+}$ & 0.5 & 0.502 & 100.4 \\
& 0 & - & - \\
& 0.3 & 0.301 & 100.3 \\
& 0.5 & 0.449 & 99.8
\end{tabular}

Table 3 Detection results of $\mathrm{Cu}^{2+}, \mathrm{Cd}^{2+}$, and $\mathrm{Hg}^{2+}$ concentration in lake water sample

\begin{tabular}{lllll}
\hline Analytes & Added (ppb) & $\begin{array}{l}\text { By this method } \\
(\mathrm{ppb})\end{array}$ & $\begin{array}{l}\text { By ICP-MS } \\
(\mathrm{ppb})\end{array}$ & Relative error \\
\hline $\mathrm{Cu}^{2+}$ & 8.0 & 7.872 & 8.018 & $-1.8 \%$ \\
$\mathrm{Cd}^{2+}$ & 8.0 & 8.176 & 8.012 & $2.1 \%$ \\
$\mathrm{Hg}^{2+}$ & 8.0 & 7.813 & 8.064 & $-3.1 \%$ \\
\hline
\end{tabular}

to many carboxyl groups, which is beneficial for the preconcentration of $\mathrm{Cu}^{2+}, \mathrm{Cd}^{2+}$, and $\mathrm{Hg}^{2+}$ to the surface of the modified electrode, as shown in Scheme 1. (ii) GO in the composite film has good conductivity, so it can quickly transfer electrochemical signals. (iii) The introduction of porphyrin as a terminal group into PGA better enhances the interaction between PGA and GO, and further improves the electron transfer.

\subsection{Interference performance of PG/GCE}

In practical detection, the interference ions might be co-deposit with the target metal ions. Thus, the electrode selectivity is very important for the analytical detection of heavy metal ions. In order to explore the selectivity of PG/GCE for simultaneous detection of $\mathrm{Cu}^{2+}, \mathrm{Cd}^{2+}$ and $\mathrm{Hg}^{2+}$, five usual kinds of foreign ions were chosen as potential interfering species during the analytical process by using DPASV under the above optimized experimental parameters. The interference experiments were performed by detecting $2.0 \mu \mathrm{M} \mathrm{Cu}^{2+}, \mathrm{Cd}^{2+}$, and $\mathrm{Hg}^{2+}$ in $0.1 \mathrm{M}$ PBS ( $\mathrm{pH}$ 6.5) containing $10 \mu \mathrm{M}$ of the interference ions including $\mathrm{K}^{+}, \mathrm{Ca}^{2+}, \mathrm{Zn}^{2+}, \mathrm{Fe}^{3+}$ and $\mathrm{Co}^{2+}$ and the changes of DPASV response current signals of the three heavy metal ions after adding the five interference ions are shown in Fig. 7A. The results showed that the peak currents of $\mathrm{Cu}^{2+}, \mathrm{Cd}^{2+}$, and $\mathrm{Hg}^{2+}$ decreased slightly after the addition of interfering metal ions, which may be due to the binding ability of these interfering metal ions to PGA. However, as seen from the Fig. 7A, the decrease of the peak currents of the three heavy metal ions is less than $20 \%$ in the presence of the interference ion with 5 -fold the detected ion concentration, indicating that PG/GCE exhibits high selectivity for $\mathrm{Cu}^{2+}, \mathrm{Cd}^{2+}$, and $\mathrm{Hg}^{2+}$ in the DPASV analysis. Fig. 7B shows the changes of DPASV response current signals of $2.0 \mu \mathrm{M} \mathrm{Cu}^{2+}, \mathrm{Cd}^{2+}$, and $\mathrm{Hg}^{2+}$ in $0.1 \mathrm{M}$ PBS (pH 6.5) after adding 
$10 \mu \mathrm{M} \mathrm{K}^{+}, \mathrm{Ca}^{2+}, \mathrm{Zn}^{2+}, \mathrm{Fe}^{3+}$ and $\mathrm{Co}^{2+}$. The decrease of the peak currents of the three heavy metal ions is less than $25 \%$, indicating that PG/GCE exhibits high selectivity for $\mathrm{Cu}^{2+}, \mathrm{Cd}^{2+}$, and $\mathrm{Hg}^{2+}$.

\subsection{Stability and reproducibility of PG/GCE}

Stability and reproducibility are two important performance properties of electrochemical sensors. The stability of PG/GCE was examined by 5 repetitive measurements of $2.0 \mu \mathrm{M} \mathrm{Cu}^{2+}$, $\mathrm{Cd}^{2+}$, and $\mathrm{Hg}^{2+}$ in $0.1 \mathrm{M}$ PBS using $\mathrm{CV}$ at the same PG/GCE electrode under the optimized experimental conditions. The change of redox peak currents is not obvious and the oxidation peak currents of the three target heavy metal ions are shown in Fig. 8A, with relative standard deviation (RSD) values of $0.34 \%$ for $\mathrm{Cu}^{2+}, 1.98 \%$ for $\mathrm{Cd}^{2+}$ and $0.23 \%$ for $\mathrm{Hg}^{2+}$, respectively. Furthermore, the PG/GCE electrode was stored in the refrigerator at $5{ }^{\circ} \mathrm{C}$ for two weeks, and the oxidation peak currents for $\mathrm{Cu}^{2+}, \mathrm{Cd}^{2+}$ and $\mathrm{Hg}^{2+}$ remained at $96.8 \%, 95.1 \%$ and $97.3 \%$ of their initial values, respectively. The obtained results indicated the good stability of the modified electrode PG/GCE. The reproducibility of the modified electrodes was also checked with five different PG/GCE electrodes prepared using the same conditions. Fig. 8B depicts the oxidation peak current changes of five different electrodes in simultaneous detection of $2.0 \mu \mathrm{M}$ $\mathrm{Cu}^{2+}, \mathrm{Cd}^{2+}$, and $\mathrm{Hg}^{2+}$ in $0.1 \mathrm{M}$ PBS under the optimized conditions. The results show that the modified electrode also has good reproducibility with the RSD of the peak currents as $3.23 \%$ for $\mathrm{Cu}^{2+}, 6.85 \%$ for $\mathrm{Cd}^{2+}, 3.14 \%$ for $\mathrm{Hg}^{2+}$, respectively. Under the optimized conditions, the changes of the oxidation peak currents with increasing the soaking time of PG/GCE in $0.1 \mathrm{M}$ PBS containing $2.0 \mu \mathrm{M} \mathrm{Cu}^{2+}, \mathrm{Cd}^{2+}$, and $\mathrm{Hg}^{2+}$ before initiating measurements are shown in Fig. 8C. When the soaking time less than 150 minutes, the PG/GCE has good stability with the RSD of the peak currents as $3.28 \%$ for $\mathrm{Cu}^{2+}, 5.86 \%$ for $\mathrm{Cd}^{2+}$, $1.69 \%$ for $\mathrm{Hg}^{2+}$, respectively.

\subsection{Practical application of PG/GCE}

In order to evaluate the high sensitivity and practical value of the modified electrode, PG/GCE was used to determine $\mathrm{Cu}^{2+}$, $\mathrm{Cd}^{2+}$, and $\mathrm{Hg}^{2+}$ concentration in lake water samples. Lake samples were pretreated by filtration and then added to $0.1 \mathrm{M}$ PBS, finally detected using the DPASV method under the optimized conditions. Because of the low concentrations of $\mathrm{Cu}^{2+}$, $\mathrm{Cd}^{2+}$, and $\mathrm{Hg}^{2+}$ in the lake samples, standard addition method was used to analyze $\mathrm{Cu}^{2+}, \mathrm{Cd}^{2+}$, and $\mathrm{Hg}^{2+}$ concentration in the lake samples. The recovery results for $\mathrm{Cu}^{2+}, \mathrm{Cd}^{2+}$, and $\mathrm{Hg}^{2+}$ are summarized in Table 2 . The recoveries of the three heavy metal ions are almost $100 \%$ (99.3-100.4\%), demonstrating that the prepared PG/GCE can be used to analyze the actual samples with high sensitivity and accuracy. Additionally, ICP-MS was also used to verify the accuracy of PG/GCE on the analysis results of real samples. As summarized in Table 3 , the results show that the $\mathrm{Cu}^{2+}, \mathrm{Cd}^{2+}$, and $\mathrm{Hg}^{2+}$ concentration obtained by two methods are consistent, and the relative error was below $3.1 \%$. It is proved that $\mathrm{PG} / \mathrm{GCE}$ has the application prospect of accurately detecting heavy metal ions in the environment.

\section{Conclusion}

In summary, the glassy carbon electrode (GCE) modified by PGA/GO composite film (PG) displayed high stability and good reproducibility for the simultaneous detection of heavy metal ions $\mathrm{Cu}^{2+}, \mathrm{Cd}^{2+}$, and $\mathrm{Hg}^{2+}$ by using DPASV method. The peak potentials of each heavy metal were well defined and sufficiently separated during the simultaneous determination of the three heavy metal ions. Due to the high affinity of PGA to heavy metal ions and the good conductivity of GO, the prepared PG/GCE electrode exhibited very high electrochemical response for the detection of the three heavy metal ions, with high sensitivity of superior to most of the reported values. Moreover, lake water detection also confirmed that the prepared PG/GCE electrode was suitable for the detection of heavy metal ions in practical samples, demonstrating the modified electrode could be used as a promising platform for the monitor and detection of heavy metal ions in environmental applications.

\section{Author contributions}

The manuscript was written through contributions of all authors. All authors have given approval to the final version of the manuscript. Wei Yi and Xiaohua He designed research; Wei Yi performed research and analyzed data; Zihua He prepared poly $(\gamma$-benzyl-glutamate); Junjie Fei gave some suggestions; and Wei Yi and Xiaohua He wrote the paper.

\section{Conflicts of interest}

There are no conflicts to declare.

\section{Acknowledgements}

This work was financially supported by the National Natural Science Foundation of China (51773063, 21475114). The assistance of Ms Huijing Han in performing the electrochemical measurements is gratefully acknowledged.

\section{References}

1 (a) P. C. Nagajyoti, K. D. Lee and T. V. M. Sreekanth, Environ. Chem. Lett., 2010, 8, 199-216; (b) D. P. Mukherjee, J. Hydrol., 2014, 517, 762-776; (c) W. T. Tsai, M. H. Nguyen, J. R. Lai, H. B. Nguyen, M. C. Lee and F. G. Tseng, Sens. Actuators, B, 2018, 265, 75-83.

2 (a) M. Mirzaei, M. Behzadi, N. M. Abadi and A. Beizaei, J. Hazard. Mater., 2011, 186, 1739-1743; (b) N. Gogoi, M. Barooah, G. Majumdar and D. Chowdhury, ACS Appl. Mater. Interfaces, 2015, 7, 3058-3067; (c) N. Chen, Y. Zhang, H. Liu, H. Ruan, C. Dong, Z. Shen and A. Wu, ACS Sustainable Chem. Eng., 2016, 4, 6509-6516.

3 S. Su, B. Chen, M. He and B. Hu, Talanta, 2014, 123, 1-9.

4 S. Wang, M. Wei and Y. Huang, J. Agric. Food Chem., 2013, 61, 4988-4996.

5 (a) G. Aragay and A. Merkoçi, Electrochim. Acta, 2012, 84, 4961; (b) L. Cui, J. Wu and H. Ju, Biosens. Bioelectron., 2015, 63, 
276-286; (c) S. K. Pandey, P. Singh, J. Singh, S. Sachan, S. Srivastava and S. K. Singh, Electroanalysis, 2016, 28, 2472-2488; (d) N. Zhang, R. Qiao, J. Su, J. Yan, Z. Xie, Y. Qiao, X. Wang and J. Zhong, Small, 2017, 13, 1604293;

(e) T. Wang and W. Yue, Electroanalysis, 2017, 29, 21782189; $(f)$ E. Chow and J. J. Gooding, Electroanalysis, 2006, 18, 1437-1448.

6 L. Xiao, H. Xu, S. Zhou, T. Song, H. Wang, S. Li, W. Gan and Q. Yuan, Electrochim. Acta, 2014, 143, 143-151.

7 (a) M. Dali, K. Zinoubi, A. Chrouda, S. Abderrahmane, S. Cherrad and N. Jaffrezic-Renault, J. Electroanal. Chem., 2018, 813, 9-19; (b) R. Kumar, T. Bhuvana and A. Sharma, RSC Adv., 2017, 7, 42146-42158; (c) S. Duan and Y. Huang, J. Electroanal. Chem., 2017, 807, 253-260; (d) H. Xing, J. Xu, X. Zhu, X. Duan, L. Lu, W. Wang, Y. Zhang and T. Yang, J. Electroanal. Chem., 2016, 760, 52-58; (e) S. Lee, J. Oh, D. Kim and Y. Piao, Talanta, 2016, 160, 528-536.

8 P. K. Sahoo, B. Panigrahy, S. Sahoo, A. K. Satpati, D. Li and D. Bahadur, Biosens. Bioelectron., 2013, 43, 293-296.

9 M. A. Deshmukh, R. Celiesiute, A. Ramanaviciene, M. D. Shirsat and A. Ramanavicius, Electrochim. Acta, 2018, 259, 930-938.

10 (a) M.-O. Park, H.-B. Noh, D.-S. Park, J.-H. Yoon and Y.-B. Shim, Electroanalysis, 2017, 29, 514-520; (b) M. B. Gumpu, M. Veerapandian, U. M. Krishnan and J. B. Rayappan, Talanta, 2017, 162, 574-582; (c) P. Gnanaprakasam, S. E. Jeena, D. Premnath and T. Selvaraju, Electroanalysis, 2016, 28, 1885-1893.

11 (a) Y. Xie, X. Tu, X. Ma, Q. Fang, L. Lu, Y. Yu, G. Liu and C. Liu, Nanotechnology, 2019, 30, 185502; (b) Y. Zuo, J. Xu, X. Zhu, X. Duan, L. Lu and Y. Yu, Microchim. Acta, 2019, 186(3), 171; (c) H. Xing, J. Xu, X. Zhu, X. Duan, L. Lu,
Y. Zuo, Y. Zhang and W. Wang, J. Electroanal. Chem., 2016, 782, 250-255; (d) Y. Zuo, J. Xu, F. Jiang, X. Duan, L. Lu, H. Xing, T. Yang, Y. Zhang and Y. Yu, J. Electroanal. Chem., 2017, 801, 146-152.

12 W. Yi, C. Ji, J. Fei and X. He, Electroanalysis, 2018, 30, 28882898.

13 (a) A. Parnsubsakul, S. Oaew and W. Surareungchai, Nanoscale, 2018, 10, 5466-5473; (b) M. Lin, M. Cho, W.-S. Choe and Y. Lee, Electroanalysis, 2016, 28, 998-1002; (c) A. Benvidi, S. Yazdanparast, M. Rezaeinasab, M. D. Tezerjani and S. Abbasi, J. Electroanal. Chem., 2018, 808, 311-320; (d) Y. Lin, K. Liu, C. Liu, L. Yin, Q. Kang, L. Li and B. Li, Electrochim. Acta, 2014, 133, 492-500.

14 A. C. Lim, H. J. Kwon, H. S. Jadhav and J. G. Seo, Electrochim. Acta, 2018, 274, 112-120.

15 W. S. Hummers Jr and R. E. Offeman, J. Am. Chem. Soc., 1958, 80, 1339.

16 X. He, C. Gao, W. Sun, W. Huang, S. Lin and D. Yan, J. Polym. Sci., Part A: Polym. Chem., 2013, 51, 1040-1050.

17 J. Babin, D. Taton, M. Brinkmann and S. Lecommandoux, Macromolecules, 2008, 41, 1384-1392.

18 C. He, M. Xie, F. Hong, X. Chai, H. Mi, X. Zhou, L. Fan, Q. Zhang, T. Ngai and J. Liu, Electrochim. Acta, 2016, 222, 1709-1715.

19 A. Abbaspour and S. M. Moosavi, Talanta, 2002, 56, 91-96. 20 X. Zhu, B. Liu, H. Hou, Z. Huang, K. M. Zeinu, L. Huang, X. Yuan, D. Guo, J. Hu and J. Yang, Electrochim. Acta, 2017, 248, 46-57.

21 M. Roushani, A. Valipou and Z. Saedi, Sens. Actuators, B, 2016, 233, 419-425.

22 P. Veerakumar, V. Veeramani, S.-M. Chen, R. Madhu and S.-B. Liu, ACS Appl. Mater. Interfaces, 2016, 8, 1319-1326. 